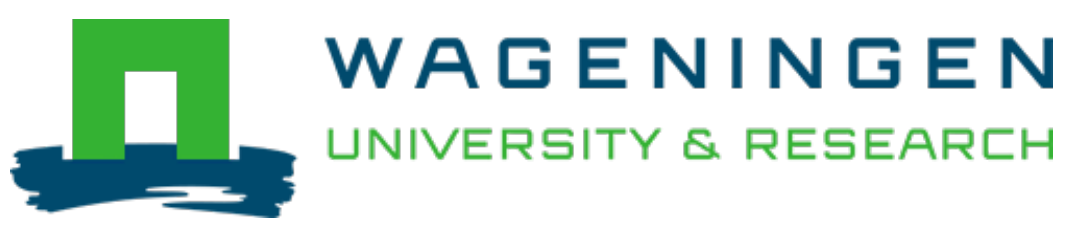

\title{
Microbiota dynamics related to environmental conditions during the fermentative production of Fen-Daqu, a Chinese industrial fermentation starter
}

\author{
International Journal of Food Microbiology \\ Zheng, X.; Yan, Z.; Nout, M.J.R.; Smid, E.J.; Zwietering, M.H. et al \\ https://doi.org/10.1016/j.ijfoodmicro.2014.05.008
}

This publication is made publicly available in the institutional repository of Wageningen University and Research, under the terms of article $25 \mathrm{fa}$ of the Dutch Copyright Act, also known as the Amendment Taverne. This has been done with explicit consent by the author.

Article 25 fa states that the author of a short scientific work funded either wholly or partially by Dutch public funds is entitled to make that work publicly available for no consideration following a reasonable period of time after the work was first published, provided that clear reference is made to the source of the first publication of the work.

This publication is distributed under The Association of Universities in the Netherlands (VSNU) 'Article $25 \mathrm{fa}$ implementation' project. In this project research outputs of researchers employed by Dutch Universities that comply with the legal requirements of Article $25 \mathrm{fa}$ of the Dutch Copyright Act are distributed online and free of cost or other barriers in institutional repositories. Research outputs are distributed six months after their first online publication in the original published version and with proper attribution to the source of the original publication.

You are permitted to download and use the publication for personal purposes. All rights remain with the author(s) and / or copyright owner(s) of this work. Any use of the publication or parts of it other than authorised under article $25 \mathrm{fa}$ of the Dutch Copyright act is prohibited. Wageningen University \& Research and the author(s) of this publication shall not be held responsible or liable for any damages resulting from your (re)use of this publication.

For questions regarding the public availability of this publication please contact openscience.library@wur.nl 


\title{
Microbiota dynamics related to environmental conditions during the fermentative production of Fen-Daqu, a Chinese industrial fermentation starter
}

\author{
Xiao-Wei Zheng a,b ${ }^{\text {, Zheng Yan }}{ }^{\text {b }}$, M.J. Robert Nout ${ }^{\text {a }}$, Eddy J. Smid ${ }^{\text {a }}$, Marcel H. Zwietering a ${ }^{\text {, Teun Boekhout }}{ }^{\text {, }}$ \\ Jian-Shu Han ${ }^{\mathrm{d}}$, Bei-Zhong Han ${ }^{\mathrm{b}, *}$ \\ a Laboratory of Food Microbiology, Wageningen University, P.O. Box 17, 6700 AA Wageningen, The Netherlands \\ b College of Food Science and Nutritional Engineering, China Agricultural University, Beijing 100083, China \\ c CBS Fungal Biodiversity Centre, Royal Netherlands Academy of Arts and Sciences (KNAW), Uppsalalaan 8, 3584 CT Utrecht, The Netherlands \\ d Shanxi Xinghuacun Fenjiu Distillery Co. Ltd., Fenyang 032205, Shanxi, China
}

\section{A R T I C L E I N F O}

\section{Article history:}

Received 6 March 2014

Received in revised form 24 April 2014

Accepted 11 May 2014

Available online 15 May 2014

\section{Keywords:}

Daqu

Starter culture

Culture-independent

Bacteria

Fungi

Canonical correspondence analysis

\begin{abstract}
A B S T R A C T
Chinese Daqu is used as a starter for liquor and vinegar fermentations. It is produced by solid state fermentation of cereal-pulse mixtures. A succession of fungi, lactic acid bacteria and Bacillus spp. was observed during the production of Daqu. Mesophilic bacteria followed by fungi, dominated the first phase of fermentation. Next, lactic acid bacteria increased in relative abundance, resulting in an increase of the acidity of Daqu. At the final stages of fermentation, Bacillus spp. and thermophilic fungi became the dominant groups, possibly due to their tolerance to low water activity and high temperature. Both culture-dependent and culture-independent analyses confirmed that Bacillus spp. were ubiquitous throughout the process. Yeast species such as Wickerhamomyces anomalus, Saccharomycopsis fibuligera and Pichia kudriavzevii were present throughout almost the entire fermentation process, but the zygomycetous fungus Lichtheimia corymbifera proliferated only during the final stages of fermentation. Canonical correspondence analysis (CCA) revealed the significance of acidity, moisture content and temperature in correlation with the composition of the microbial communities at different stages.
\end{abstract}

(c) 2014 Elsevier B.V. All rights reserved.

\section{Introduction}

Chinese liquor (a traditional distilled alcoholic beverage) and vinegar are important commercial fermented products in China with an annual production of about 12 million metric ton and 5 million metric ton in the country, respectively (Han, 2007). Daqu serves as a fermentation inoculum, and it makes a considerable contribution to the flavor of Chinese liquor and traditional Chinese vinegar (Wu et al., 2009). It is an intermediate natural fermentation product that contains metabolically active microorganisms and enzymes. It is an essential ingredient responsible for the release of fermentable sugars from sorghum starch. Generally, Daqu can be classified into four major types, i.e. light-flavor Daqu, strong-flavor Daqu, sauceflavor Daqu and miscellaneous-flavor Daqu (Zheng et al., 2011). Fen-Daqu is a light-flavor Daqu that is prepared from barley and

\footnotetext{
* Corresponding author at: College of Food Science and Nutritional Engineering, Chin Agricultural University. P.O. BOX 398, No. 17 Qinghua East Road, Beijing 100083, China. Tel./fax: +86106273 7078 .

E-mail addresses: xiaowei.zheng@wur.nl (X.-W. Zheng),bioyanzheng@126.com (Z. Yan), rob.nout@wur.nl (M.J.R. Nout), eddy.smid@wur.nl (E.J. Smid), marcel.zwietering@wur.nl (M.H. Zwietering), t.boekhout@cbs.knaw.nl (T. Boekhout), hanjianshu2013@163.com (J.-S. Han),hbz@cau.edu.cn (B.-Z. Han).
}

peas in five steps: (i) formulation of ingredients; (ii) grinding and mixing; (iii) shaping; (iv) incubation (about 1 month); and (v) maturation (about 6 months). The incubation stage, also called the fermentation stage, as described by Zheng et al. (2012) can be divided into seven stages according to the core temperature profile of Daqu during its production (Fig. 1).

Fen-Daqu is produced using traditional fermentation technology and contains microorganisms that are naturally present in the ingredients (i.e., barley and peas) and its production environment (i.e., tools, soil, air, and machines) (Lei, 2011). Recently, the microbial diversity in various types of Daqu has been investigated (Lei, 2011; Wang et al., 2011; Zheng et al., 2012). However, limited data have been reported on the microbial communities prevailing during Daqu production (Li et al., 2013). With their study, only a cultureindependent cloning method was used, and the microbial dynamics in relation with the environmental conditions during Daqu fermentation processes has not been reported. Therefore, the objectives of this study were to analyze changes in temperature, acidity, moisture content and microbial communities during Daqu production and to understand the predominance and succession of microbes during its fermentation process as a function of dynamics of environmental conditions. 


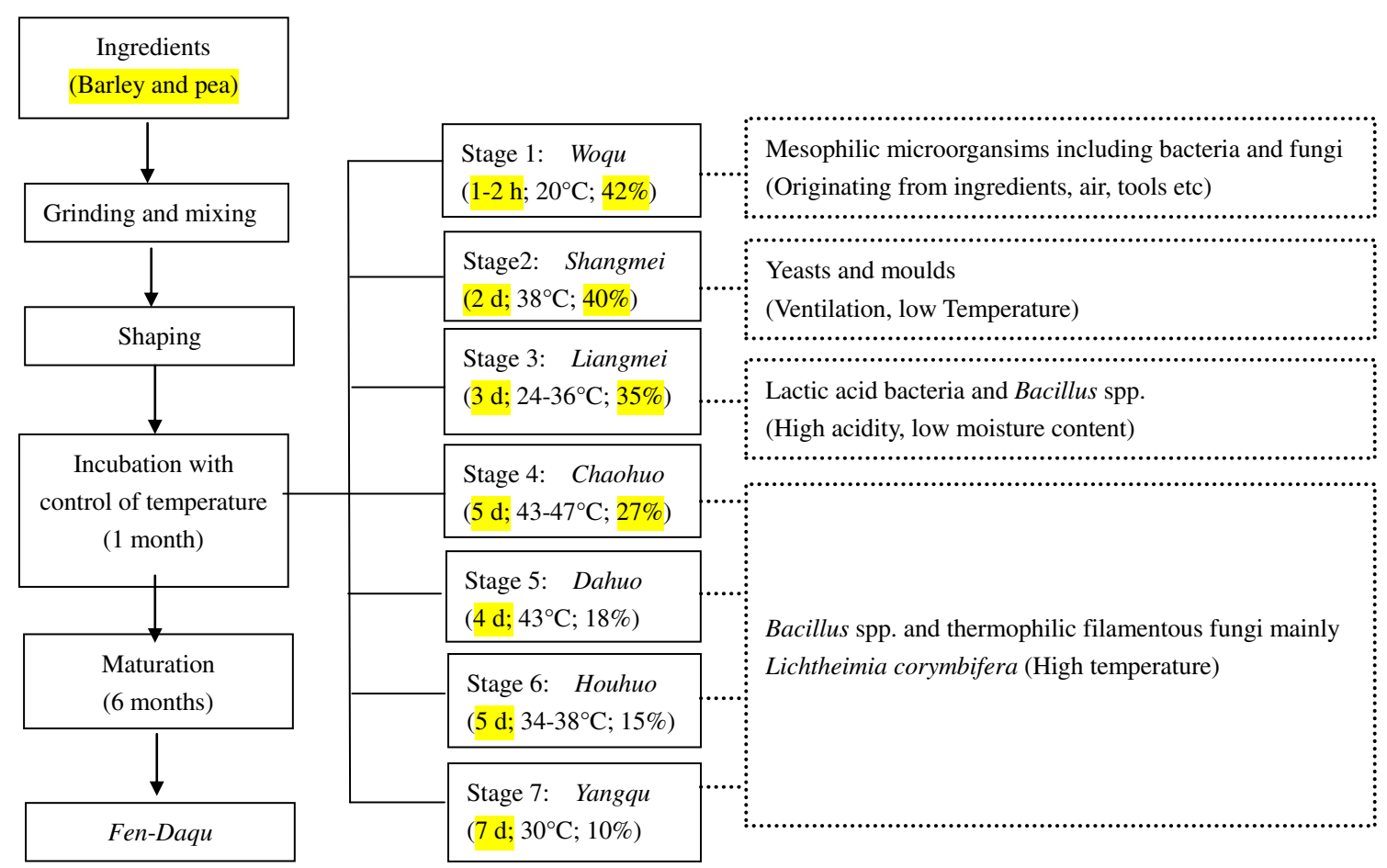

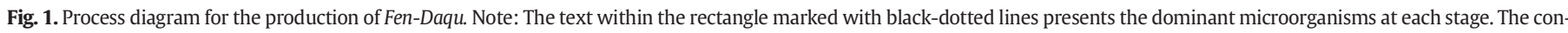
tent given in brackets presents the factors that determine microbial diversity at that stage. The percentage (\%) represents the moisture content in the stages.

\section{Materials and methods}

\subsection{Sampling}

Fen-Daqu samples were obtained from Shanxi Xinghuacun Fenjiu Distillery Co. Ltd. (Fenyang, Shanxi, China) during the month of October 2009, which is the season of Daqu production. Samples were separately taken from four independent processes and collected at the seven production stages, as shown in Fig. 1. At each of the sampling events, approximately $100 \mathrm{~g}$ of Daqu was aseptically collected in triplicate (in order to obtain adequate representation, three blocks were randomly selected from upper, middle and lower layers), ground and pooled to provide an experimental Daqu powder sample. Samples were then collected into sterile Stomacher bags (Stomacher ${ }^{\circledR}$ Lab System, London, UK), and transported to the laboratory in a cooler box.

\subsection{Microbiological analysis-culture-dependent methods}

\subsubsection{Enumeration and isolation}

Samples from all 7 stages, each weighing $10 \mathrm{~g}$ were transferred to Stomacher bags and homogenized with $90 \mathrm{~mL}$ sterile PPS (peptone physiological salt) solution containing $(\mathrm{g} / \mathrm{L})$ peptone (Oxoid LP0034) 1 , and $\mathrm{NaCl} 8.5$, in a Stomacher Lab-blender 400 . Portions $(1 \mathrm{~mL})$ of the diluted suspensions were plated on different selective agar media. Total aerobic bacteria and spores, lactic acid bacteria, Enterobacteriaceae and fungi were enumerated on Plate Count Agar (PCA; Oxoid CM035), MRSA (Oxoid CM0361), Violet Red Bile Glucose Agar (VRBGA; Oxoid CM0485) and Malt Extract Agar (MEA; Oxoid CM0059), respectively. These were incubated at different temperatures $\left(30{ }^{\circ} \mathrm{C}, 37^{\circ} \mathrm{C}\right.$ and $55^{\circ} \mathrm{C}$ ) for the isolation and enumeration (by recording the number of $\mathrm{CFU}$ ) of specific groups of micro-organisms (Zheng et al., 2012).

\subsubsection{Extraction of DNA from pure culture}

Single colony isolates for subsequent DNA extractions were obtained from the counted plates. The plates corresponding to a number of colonies less than or equal to 50 , were selected to perform isolations. The square root of the total number of colonies was randomly picked up from both duplicate plates. After purification, isolates were grown under the same conditions as used previously for cultivation. Cells at stationary phase were collected by centrifugation at $9000 \mathrm{~g}$ for further extraction of total DNA. The genomic DNA of bacteria and fungi was extracted according to the method described by Zheng et al. (2012).

\subsubsection{Nucleotide sequence accession numbers}

The primers used in this study are listed in Table 1. The 16S rRNA gene sequences of the bacteria in this study were deposited in GenBank under the accession numbers KJ526822-KJ526949; the 26S rRNA and ITS gene sequences of the yeasts were deposited in GenBank under the accession numbers KJ526950-KJ526985 and KJ527033-KJ527069, respectively; the ITS gene sequences of the molds were deposited in GenBank under the accession numbers KJ527009-KJ527032.

\subsection{Microbiological analysis-culture-independent methods}

\subsubsection{PCR-DGGE analysis and bands excision}

Total DNA was extracted from Daqu powder by the same method used previously (Zheng et al., 2012). Two sets of universal primers were tested for the amplification of a fragment of the 16S rRNA gene and the 26S rRNA gene (Table 1). Amplifications, DGGE analysis and identification of bands of interest were performed as described by Zheng et al. (2012). The sequences of excised bands in this study were deposited in GenBank under the accession numbers KJ526994-KJ527008 for bacteria and the accession numbers KJ526986-KJ526993 for fungi.

\subsection{Physicochemical analysis-determination of temperature and relative humidity}

The surface temperature of Daqu was recorded with a calibrated mini infrared thermometer gun (UNI-T UT301A, Beijing, China) at the time of sampling. The relative humidity $(\mathrm{RH})$ of the incubation room was recorded with a humidity/temperature logger (Testo 175-H2, Shanghai, China). The continuous online detection of the core temperature of Daqu and 
Table 1

PCR primers used in this study.

\begin{tabular}{|c|c|c|c|}
\hline Primer & Sequence $\left(5^{\prime} \rightarrow 3^{\prime}\right)$ & Aims & Reference \\
\hline B-for ${ }^{\mathrm{a}}$ & AGAGTTTGATCCTGGCTCAG & Amplification 16S rRNA gene and sequencing for bacteria & (Lima et al., 2012) \\
\hline B-rev ${ }^{\mathrm{a}}$ & AAGGAGGTGATCCAGCCGCA & & \\
\hline NL1-for & GCATATCAATAAGCGGAGGAAAAG & D1 and D2 domains of 26S rRNA gene and sequencing for yeasts & (Zheng et al., 2012) \\
\hline RLR3R-rev & GGTCCGTGTTTCAAGAC & & \\
\hline ITS5-for & GGAAGTAAAAGTCGTAACAAGG & Amplification of ITS1-5.8S-ITS2 gene and sequencing for yeasts & (Zheng et al., 2012) \\
\hline ITS4-rev & TCCTCCGCTTATTGATATGC & & \\
\hline V9G-for & TTACGTCCCTGCCCTTTGTA & Amplification of ITS1-5.8S-ITS2 gene and sequencing for molds & (Zheng et al., 2012) \\
\hline LS266-rev & GCATTCCCAAACAACTCGACTC & & \\
\hline EUB968GC-for & $\frac{\text { CGCCCGGGGCGCGCCCCGGGCGGGGCGGGGGCAGGGG }}{\text { AACGCGAAGAACCTTAC }}$ & Bacterial DGGE & (Zheng et al., 2012) \\
\hline EUBL1401-rev & CGGTGTGTACAAGACCC & & \\
\hline EUB968-for & AACGCGAAGAACCTTAC & Sequencing of excised bands from bacterial DGGE & (Zheng et al., 2012) \\
\hline EUBL1401-rev & CGGTGTGTACAAGACCC & & \\
\hline NL1GC-for & $\frac{\text { CGCCCGCCGCGCGCGGCGGGCGGGGCGGGGGCACGGG }}{\text { GCATATCAATAAGCGGAGGAAAAG }}$ & Fungal DGGE & (Zheng et al., 2012) \\
\hline LS2-rev & ATT CCC AAA CAA CTCGAC TC & & \\
\hline NL1-for & GCATATCAATAAGCGGAGGAAAAG & Sequencing of excised bands from fungal DGGE & (Zheng et al., 2012) \\
\hline LS2-rev & ATT CCC AAA CAA CTCGAC TC & & \\
\hline
\end{tabular}

The GC clamp is underlined.

${ }^{a}$ for: forward; rev: reverse.

room temperature was performed with electronic temperature sensors (iButton, Maxim, USA) which were inserted into the center of the Daqu blocks (see Supplementary data, Fig. S1) and stuck on the wall of incubation room. For this purpose, during stage 1, three Daqu blocks were randomly selected from each incubation room and labeled. The i-buttons recorded data at hourly intervals until the end of stage 7. Means and standard deviations were calculated.

\subsection{Statistical analysis}

DGGE data and environmental data were analyzed by canonical correspondence analysis (CCA), using CANOCO 4.5 for Windows software (Biometris, The Netherlands). Significance was tested by the distribution-free Monte Carlo test using 199 random permutations.

\section{Results}

\subsection{Changes in viable cell counts over time during Daqu fermentation}

Changes in microbial counts were monitored during the seven stages of Fen-Daqu fermentation (see Table 2). The average bacterial counts of the various groups at the start of fermentation (stage 1) were rather low and varied between $3.4 \mathrm{log} \mathrm{cfu} / \mathrm{g}$ and $6.2 \mathrm{log} \mathrm{cfu} / \mathrm{g}$ with mesophilic bacteria dominant. After this stage, total counts increased over time, reaching values as high as 9-11 log cfu/g for mesophilic and thermophilic bacteria and bacterial spores, and 5-7 log cfu/g for Enterobacteriaceae and lactic acid bacteria. The levels of mesophilic and thermophilic bacteria and bacterial spores remained at the same level $(P<0.05)$ after stage 5 (Dahuo). In the case of lactic acid bacteria, the highest numbers were obtained at stage 3 which decreased thereafter (Table 2). With respect to fungi, average levels of 5.2 to $8.1 \mathrm{log} \mathrm{cfu} / \mathrm{g}$ were observed. The number of fungi increased approximately 3 orders of magnitude during stage 2 (Shangmei) and showed a declining trend until the final stage 7 (Yangqu).

\subsection{Microbial communities during fermentation}

By combining data from culture-dependent and -independent analysis methods, evidence for the presence of 22 bacteria species and one uncultured bacterium was found in Daqu, representing the genera Bacillus, Lactobacillus, Acetobacter, Lactococcus, Staphylococcus, Weissella, Pediococcus, Microbacterium, Georgenia and the Enterobacteriaceae family (Table 3). Members of the genus Bacillus comprised approximately $50 \%$ of total bacterial isolates with Bacillus licheniformis as the most common species. DGGE analysis confirmed the high relative abundance of Bacillus spp. throughout the fermentation process. Weissella cibaria and Weissella confusa were dominant during Daqu fermentation and were present in different ratios during each fermentation stage. Apart

Table 2

Changes of viable microbial counts (log cfu/g), $\mathrm{pH}$, and acidity during fermentation of Fen-Daqu.

\begin{tabular}{|c|c|c|c|c|c|c|c|}
\hline & \multicolumn{7}{|c|}{ Fermentation stages ${ }^{*}$} \\
\hline & Stage 1 & Stage 2 & Stage 3 & Stage 4 & Stage 5 & Stage 6 & Stage 7 \\
\hline $\operatorname{TMAB}\left(30^{\circ} \mathrm{C}\right)$ & $6.2 \pm 0.1^{\mathrm{a}}$ & $8.2 \pm 0.3^{b}$ & $9.6 \pm 0.1^{\mathrm{c}}$ & $8.5 \pm 0.1^{b}$ & $10.8 \pm 0.4^{\mathrm{d}}$ & $10.4 \pm 0.9^{\mathrm{d}}$ & $10.4 \pm 0.3^{\mathrm{d}}$ \\
\hline $\operatorname{TTAB}\left(55^{\circ} \mathrm{C}\right)$ & $3.5 \pm 0.3^{\mathrm{a}}$ & $5.2 \pm 1.3^{\mathrm{b}}$ & $5.3 \pm 1.1^{\mathrm{b}}$ & $7.2 \pm 1.0^{c}$ & $8.1 \pm 0.3^{\mathrm{cd}}$ & $8.6 \pm 0.6^{\mathrm{d}}$ & $8.5 \pm 0.5^{\mathrm{cd}}$ \\
\hline Mesophilic aerobic bacterial endospore $\left(30^{\circ} \mathrm{C}\right)$ & $4.1 \pm 0.5^{\mathrm{a}}$ & $5.9 \pm 0.4^{\mathrm{b}}$ & $5.1 \pm 0.2^{\mathrm{b}}$ & $7.3 \pm 0.2^{c}$ & $9.6 \pm 1.0^{\mathrm{e}}$ & $8.7 \pm 0.6^{\mathrm{d}}$ & $8.8 \pm 0.6^{\mathrm{de}}$ \\
\hline Thermophilic aerobic bacterial endospore $\left(55^{\circ} \mathrm{C}\right)$ & $3.7 \pm 0.1^{\mathrm{a}}$ & $5.9 \pm 0.4^{\mathrm{b}}$ & $5.9 \pm 0.4^{\mathrm{b}}$ & $7.4 \pm 1.1^{\mathrm{c}}$ & $8.4 \pm 0.4^{\mathrm{cd}}$ & $8.8 \pm 0.3^{\mathrm{d}}$ & $8.5 \pm 0.4^{\mathrm{cd}}$ \\
\hline Lactic acid bacteria & $4.9 \pm 0.3^{\mathrm{a}}$ & $5.7 \pm 0.2^{\mathrm{bc}}$ & $6.5 \pm 0.1^{\mathrm{d}}$ & $6.3 \pm 0.1^{\mathrm{cd}}$ & $6.1 \pm 0.7^{\mathrm{cd}}$ & $6.0 \pm 0.5^{\mathrm{cd}}$ & $5.3 \pm 0.6^{\mathrm{ab}}$ \\
\hline Enterobacteriaceae & $3.4 \pm 0.2^{\mathrm{a}}$ & $3.8 \pm 0.4^{\mathrm{ab}}$ & $4.2 \pm 0.8^{\mathrm{bc}}$ & $5.0 \pm 0.2^{\mathrm{d}}$ & $4.7 \pm 0.2^{\mathrm{cd}}$ & $4.6 \pm 0.5^{\mathrm{cd}}$ & $4.1 \pm 0.5^{\mathrm{bc}}$ \\
\hline Fungi & $5.2 \pm 0.4^{\mathrm{a}}$ & $8.1 \pm 0.4^{\mathrm{d}}$ & $7.7 \pm 0.2^{\mathrm{cd}}$ & $7.3 \pm 0.1^{\mathrm{bc}}$ & $7.4 \pm 0.3^{\mathrm{bc}}$ & $7.4 \pm 0.5^{\mathrm{bc}}$ & $7.2 \pm 0.3^{b}$ \\
\hline $\mathrm{pH}$ & $4.3 \pm 0.1^{\mathrm{a}}$ & $4.2 \pm 0.1^{\mathrm{a}}$ & $4.4 \pm 0.3^{\mathrm{a}}$ & $6.1 \pm 0.6^{\mathrm{b}}$ & $6.8 \pm 0.1^{c}$ & $6.8 \pm 0.1^{\mathrm{c}}$ & $6.9 \pm 0.1^{c}$ \\
\hline Acidity (g lactic acid/kg dry matter) & $1.4 \pm 0.2^{\mathrm{a}}$ & $4.6 \pm 0.5^{\mathrm{d}}$ & $4.2 \pm 0.3^{\mathrm{d}}$ & $3.7 \pm 0.4^{\mathrm{c}}$ & $3.1 \pm 0.7^{\mathrm{bc}}$ & $3.1 \pm 0.4^{\mathrm{b}}$ & $3.3 \pm 0.5^{b c}$ \\
\hline
\end{tabular}

TMAB: total mesophilic aerobic bacteria.

TTAB: total thermophilic aerobic bacteria.

Value represent means $\pm \mathrm{SD}(n=4)$. Means with different superscripts are significantly different horizontally (one-way ANOVA; $P<0.05)$.

* Stage 1: Woqu; stage 2: Shangmei; stage 3: Liangmei; stage 4: Chaohuo; stage 5: Dahuo; stage 6: Houhuo; stage 7: Yangqu. 
Table 3

Microbiota composition at each stage of Fen-Daqu fermentation.

\begin{tabular}{|c|c|c|c|c|c|c|c|c|}
\hline & & \multicolumn{7}{|c|}{ Fen-Daqu fermentation stages ${ }^{\mathrm{a}}$} \\
\hline & & Stage 1 & Stage 2 & Stage 3 & Stage 4 & Stage 5 & Stage 6 & Stage 7 \\
\hline \multirow[t]{23}{*}{ Bacteria } & A. pasterianus & & {$[11.8]+{ }^{(I)}$} & & & & {$[6.25]+{ }^{(I)}$} & \\
\hline & A. tropicalis & & & {$[5]+{ }^{(I)}$} & & & & \\
\hline & B. anthracis/B. cereus & $+{ }^{(\mathrm{D})}$ & & {$[15]+{ }^{(I)}$} & & $+{ }^{(\mathrm{D})}$ & $+^{(\mathrm{D})}$ & $+^{(\mathrm{D})}$ \\
\hline & B. amyloliquefaciens & & & & & & {$[12.5]+{ }^{(I)}$} & \\
\hline & B. circulans & & & {$[5]+{ }^{(I)}$} & & & & \\
\hline & B. licheniformis & {$[37.5]+{ }^{(\mathrm{I} / \mathrm{D})}$} & {$[23.5]+{ }^{(\mathrm{I} / \mathrm{D})}$} & {$[15]+{ }^{(1 / D)}$} & {$[81.25]+{ }^{(\mathrm{I} / \mathrm{D})}$} & {$[88.2]+{ }^{(\mathrm{I} / \mathrm{D})}$} & {$[43.75]+{ }^{(I / D)}$} & {$[50]+{ }^{(\mathrm{I} / \mathrm{D})}$} \\
\hline & B. megaterium & $+^{(\mathrm{D})}$ & & {$[15]+{ }^{(\mathrm{I} / \mathrm{D})}$} & & $+^{(\mathrm{D})}$ & & $+^{(\mathrm{D})}$ \\
\hline & B. pumilus & {$[6.25]+{ }^{(I)}$} & {$[11.8]+{ }^{(\mathrm{I} / \mathrm{D})}$} & {$[10]+{ }^{(I)}$} & & & {$[25]+{ }^{(I)}$} & \\
\hline & B. subtilis & $+{ }^{(\mathrm{D})}$ & {$[23.5]+{ }^{(I)}$} & $+{ }^{(\mathrm{D})}$ & & & & {$[25]+{ }^{(I / D)}$} \\
\hline & Enterobacter sp./Escherichia sp. & {$[25]+{ }^{(I)}$} & {$[23.5]+{ }^{(I)}$} & {$[15]++^{(I)}$} & & & & \\
\hline & E. aerogenes & $+^{(D)}$ & & $+^{(\mathrm{D})}$ & $+{ }^{(\mathrm{D})}$ & $+^{(\mathrm{D})}$ & & \\
\hline & Georgenia sp. & {$[6.25]+{ }^{(1)}$} & & & & & & \\
\hline & Lb. curvatus/Lb. sakei & & {$[5.8]+{ }^{(I)}$} & & & & & \\
\hline & Lb. plantarum & $+{ }^{(\mathrm{D})}$ & & {$[10]+{ }^{(I)}$} & $+{ }^{(\mathrm{D})}$ & $+[11.8]^{(/ / D)}$ & $+^{(\mathrm{D})}$ & $+^{(\mathrm{D})}$ \\
\hline & Lb. sanfranciscensis & & $+^{(\mathrm{D})}$ & & $+{ }^{(D)}$ & $+{ }^{(D)}$ & $+^{(\mathrm{D})}$ & \\
\hline & Lc. lactis & {$[12.5]+{ }^{(1)}$} & & & & & & \\
\hline & Microbacterium sp. & & & {$[5]+{ }^{(I)}$} & & & & \\
\hline & Ped.pentosaceus & {$[12.5]+{ }^{(I)}$} & & {$[5]+{ }^{(I)}$} & {$[18.75]+{ }^{(I)}$} & & {$[12.5]+{ }^{(1)}$} & {$[12.5]+{ }^{(\mathrm{I})}$} \\
\hline & S. epidermidis & & & & & & & {$[12.5]+{ }^{(\mathrm{I})}$} \\
\hline & S. saprophyticus & $+{ }^{(\mathrm{D})}$ & & & $+{ }^{(D)}$ & $+^{(\mathrm{D})}$ & $+^{(\mathrm{D})}$ & $+(D)$ \\
\hline & Uncultured bacterium & & $+^{(\mathrm{D})}$ & $+^{(\mathrm{D})}$ & & $+^{(\mathrm{D})}$ & $+^{(\mathrm{D})}$ & $+^{(\mathrm{D})}$ \\
\hline & Ws. cibaria & $+{ }^{(\mathrm{D})}$ & $+^{(\mathrm{D})}$ & $+^{(\mathrm{D})}$ & $+^{(\mathrm{D})}$ & $+{ }^{(\mathrm{D})}$ & $+^{(\mathrm{D})}$ & $+^{(\mathrm{D})}$ \\
\hline & Ws. confusa & $+{ }^{(\mathrm{D})}$ & $+^{(\mathrm{D})}$ & $+^{(\mathrm{D})}$ & $+^{(\mathrm{D})}$ & $+{ }^{(\mathrm{D})}$ & $+^{(\mathrm{D})}$ & $+^{(\mathrm{D})}$ \\
\hline \multirow[t]{5}{*}{ Yeasts } & D. hansenii & & & & & $+{ }^{(\mathrm{D})}$ & $+^{(\mathrm{D})}$ & \\
\hline & P. kudriavzevii & & {$[38.4]+{ }^{(I / D)}$} & {$[23.1]+{ }^{(I / D)}$} & {$[28.5]++^{(I / D)}$} & {$[8.3]+{ }^{(\mathrm{I} / \mathrm{D})}$} & {$[25]+{ }^{(I / D)}$} & {$[28.5]+{ }^{(I / D)}$} \\
\hline & Pseudozyma sp. & {$[7.7]+{ }^{(I)}$} & & & & & & \\
\hline & Sm. fibuligera & $+{ }^{(D)}$ & $+^{(\mathrm{D})}$ & & $++^{(\mathrm{D})}$ & $+{ }^{(\mathrm{D})}$ & $+^{(\mathrm{D})}$ & $+^{(\mathrm{D})}$ \\
\hline & W. anomalus & {$[46.1]+{ }^{(\mathrm{I} / \mathrm{D})}$} & {$[23]+{ }^{(I / D)}$} & {$[69.2]+{ }^{(\mathrm{I} / \mathrm{D})}$} & {$[71.4]+{ }^{(\mathrm{I} / \mathrm{D})}$} & {$[66.7]+{ }^{(\mathrm{l} / \mathrm{D})}$} & {$[37.5]+{ }^{(1 / D)}$} & {$[28.5]+{ }^{(\mathrm{I} / \mathrm{D})}$} \\
\hline \multirow[t]{8}{*}{ Filamentous fungi } & Alternaria sp. & & & {$[7.6]+{ }^{(I)}$} & & & & {$[7.2]+{ }^{(I)}$} \\
\hline & Asp. versicolor & & & & & & {$[6.2]+{ }^{(I)}$} & \\
\hline & Cladosporium sp. & {$[23.1]+{ }^{(1)}$} & & & & & & \\
\hline & L. corymbifera & & & & & {$[25]+{ }^{(I)}$} & {$[25]+(\mathrm{I})$} & {$[35.8]+{ }^{(\mathrm{I})}$} \\
\hline & Penicillium sp. & {$[15.3]+{ }^{(I)}$} & & & & & & \\
\hline & Phoma sp. & {$[7.7]+{ }^{(\mathrm{I})}$} & & & & & & \\
\hline & Rhizomucor pusillus & & & & & & {$[6.2]+{ }^{(1)}$} & \\
\hline & R. stolonifer & & {$[38.4]+{ }^{(\mathrm{I})}$} & & & & & \\
\hline
\end{tabular}

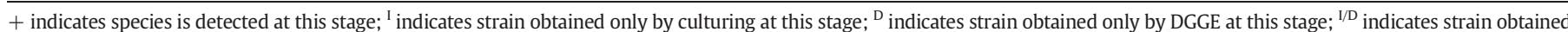

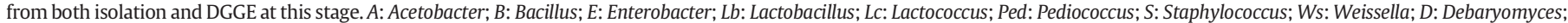

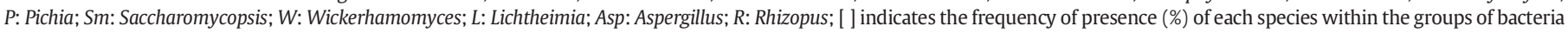
or within the groups of yeasts and molds at each stage of fermentation.

a Stage 1: Woqu; stage 2: Shangmei; stage 3: Liangmei; stage 4: Chaohuo; stage 5: Dahuo; stage 6: Houhuo; stage 7: Yangqu.

from Bacillus sp. and Weissella sp., Pediococcus pentosaceus was also found frequently.

A total of 5 yeast species were obtained of which Pichia kudriavzevii, Saccharomycopsis fibuligera and Wickerhamomyces anomalus were detected in six, six and seven stages, respectively (Table 3). Among the filamentous fungi, the zygomycetous species Lichtheimia corymbifera (formerly Absidia corymbifera) appeared during stage 5 and increased in relative abundance towards the end of the fermentation (Table 3).

\subsection{Changes in environmental factors during fermentation}

The $\mathrm{pH}$ of Daqu increased steadily after stage 3 of the fermentation process, the titratable acidity increased rapidly during stage 2 , reaching the maximum value of approximately $5 \mathrm{~g} / \mathrm{kg}$ at the end of this stage, followed by a decline (Table 2).

Changes in core and surface temperatures of Daqu blocks and of the incubation room, as well as relative humidity and moisture content that occurred during the Daqu fermentation process were monitored continuously (Fig. 2). The core temperature increased from $20{ }^{\circ} \mathrm{C}$ to $52{ }^{\circ} \mathrm{C}$ between stage 1 and stage 5 , and thereafter decreased rapidly to ambient room temperature in stage 6 . A gradual decrease of moisture content took place throughout the whole process, from $40 \mathrm{~g}$ water/100 $\mathrm{g}$ Daqu at the start to around $10 \mathrm{~g}$ water/100 $\mathrm{g}$ Daqu at the final stage. The changes in room temperature were less pronounced than those of the core of the Daqu blocks. With increasing temperature, the RH of incubation room dropped from approximately $100 \%$ to $20 \%$.

\subsection{Microbiota composition in relation to environmental variables}

Canonical correspondence analysis (CCA) was carried out using abundant DGGE bands together with environmental variables. Speciesenvironment correlations for both axes were higher than 0.99 (canonical coefficients), suggesting that microbial diversity was strongly correlated with environmental factors. In the CCA triplot (Fig. 3), the length of arrows indicated the relative importance of that environmental factor in explaining variation in microbial profiles, while the angle between the arrows (environmental factor-environmental factor or environmental factor-species) indicated the degree to which they were correlated. It shows that acidity, $\mathrm{pH}$ and surface temperature were the three most important environmental variables which could be correlated with the microbial diversity in different samples, since the lengths of these arrows are longer than those of others. Moisture content was the sole environmental factor that correlated with the microbial diversity at stages 3 and 7. Acidity correlated with the composition of the microbial community of stage 2 , in which a relatively high abundance of Ws. confusa, Ws. cibaria, Bacillus cereus, Bacillus pumilus and P. kudriavzevii was found. Temperature and $\mathrm{pH}$ were found to be strongly correlated with the composition of the microbiota during the stages 4, 5 and 6. 


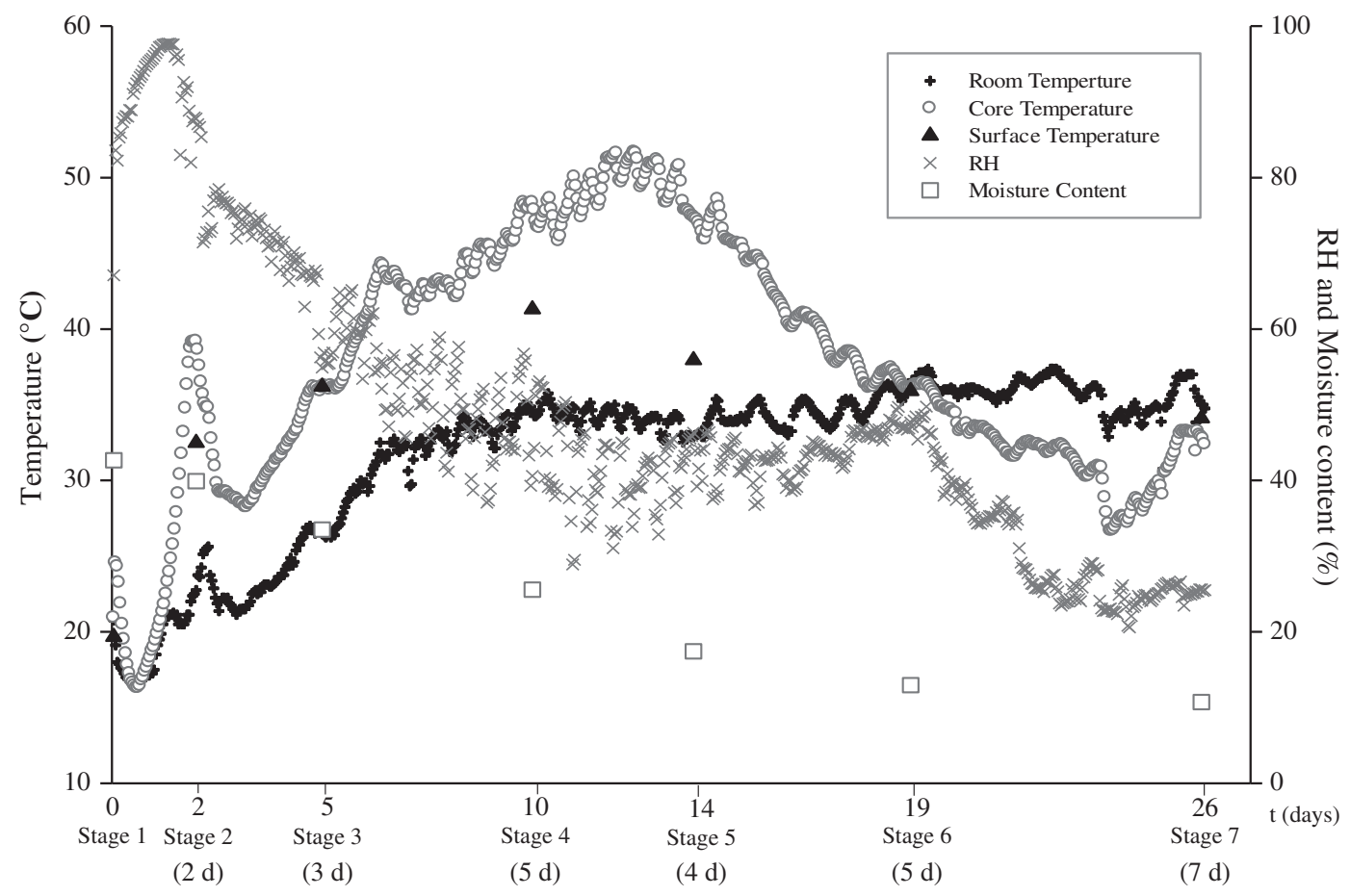

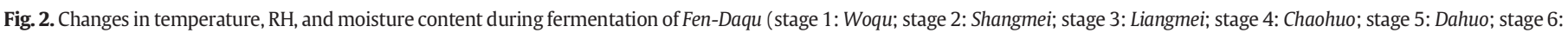
Houhuo; stage 7: Yangqu).

\section{Discussion and conclusions}

This study showed that species of the genus Bacillus are predominant during all stages of Fen-Daqu fermentation. By combining both culturedependent and culture-independent data, stage 3 was identified as the stage with the highest diversity of Bacillus spp. This result is in agreement with the data of Yan et al. (2013). In our study, seven Bacillus species, namely Bacillus anthracis/B. cereus, Bacillus amyloliquefaciens, Bacillus circulans, B. licheniformis, Bacillus megaterium, B. pumilus, and Bacillus

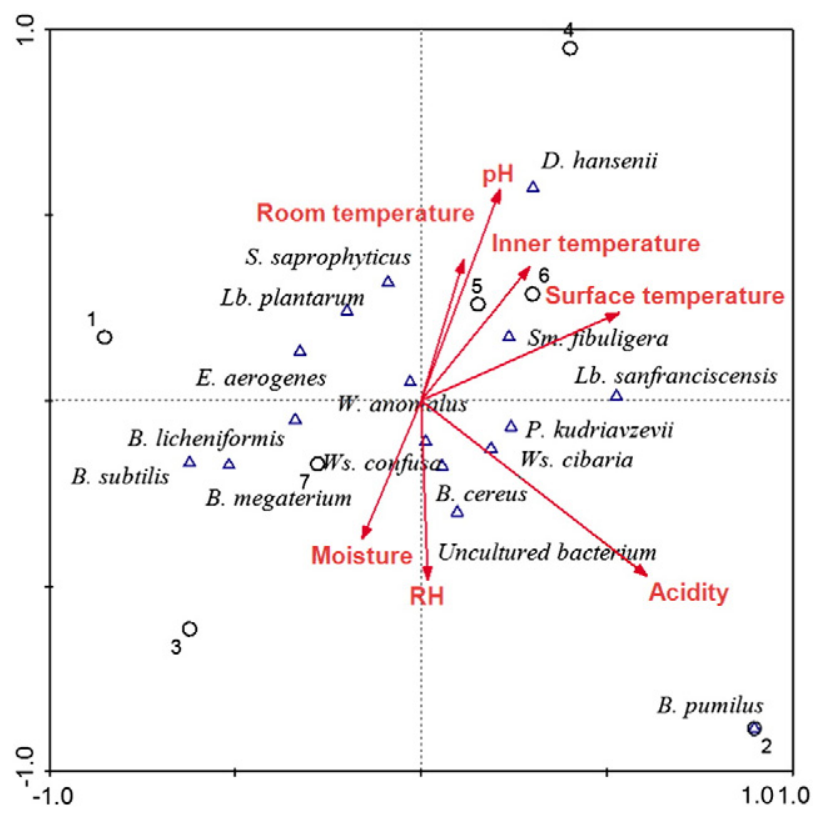

Fig. 3. Canonical correspondence analysis (CCA) of DGGE community profiles from Daqu samples from the 7 stages. Numbers refer to the different stages, arrows refer to different environmental factors, and triangles refer to the individual abundant microbial species. subtilis, were found during the whole Daqu fermentation process, whereas almost all these species were detected simultaneously at stage 3 . Of these bacilli, only B. licheniformis and B. subtilis were found in the study of Fen-Daqu production by Li et al. (2013). This result emphasizes the importance of using two complementary methods because higher numbers of species could be obtained. Bacillus spp. can survive harsh environmental conditions such as drying (Deng et al., 2012). Daqu after stage 3 became dry due to evaporation, caused by the use of forced ventilation in order to control the incubation temperature during stage 3. This explains the decrease of both room temperature and core temperatures in Fig. 2. As a result, the moisture content of Daqu decreased. Zhao et al. (2011) reported that bacilli have a better ability to survive under low moisture conditions than other bacteria. Canonical correspondence analysis also revealed the significance of moisture content in correlation with the microbial communities at this stage (Fig. 3).

The number of thermophilic bacteria and bacterial spores increased from 5.9 at stage 3 to $8.8 \log \mathrm{cfu} / \mathrm{g}$ at stage 6 (Table 2), when the diversity of Bacillus spp. decreased. Correspondence analysis indicated that $\mathrm{pH}$ and temperature were the most important factors that correlated with the composition of the microbial community during the stages 4,5 and 6 . The core temperature during these three stages reached a maximum of about $52{ }^{\circ} \mathrm{C}$ between stages 4 and 5 (Fig. 2). Such high temperature is expected to have a selective effect, favoring thermotolerant, aerobic endospore-forming bacteria. Only Bacillus spp., such as $B$. licheniformis and B. subtilis, are able to grow between 50 and $60{ }^{\circ} \mathrm{C}$ (Burgess et al., 2010). This may be the reason why members of the genus Bacillus spp. were dominating the microbial community during the last four stages. This could also explain why B. licheniformis and $B$. subtilis were encountered frequently in strong or sauce flavor Daqu (Wang et al., 2011) in which fermentation temperatures are even higher than in Fen-Daqu.

LAB also play a role in the production of Daqu (Zheng et al., 2011), especially Lactobacillus spp. (Li et al., 2013). Acidity was recognized as the most significant factor that correlated with the composition of the microbial communities of stage 2 (Fig. 3 ). The increase in acidity correlates with the occurrence of high numbers of LAB and fungi, especially 
Lactobacillus sanfranciscensis, Ws. cibaria, Ws. confusa, W. anomalus and P. kudriavzevii.

The fungal community associated with Fen-Daqu fermentation was found to be less diverse than the bacterial one. A succession of yeast species during fermentation could not be observed. Li et al. (2013) reported the predominance of $P$. kudriavzevii in Fen-Daqu; however, in our study two other yeasts species ( $\mathrm{Sm}$. fibuligera and $W$. anomalus) were predominant during Daqu fermentation, since they occurred during almost the entire production process. Sm. fibuligera has been reported to degrade and assimilate raw starch as a carbon source (Chi et al., 2009) so it may contribute to the formation of fermentable carbohydrates for the subsequent alcoholic fermentation. W. anomalus and P. kudriavzevii are known as ester-producing yeasts and a higher abundance of these organisms correlates with an elevated concentration of esters in liquor (Li et al., 2012; Wu et al., 2012).

Filamentous fungi are commonly used in solid state fermentations, because of their relatively high tolerance to low water activity and their production of hydrolytic enzymes (Rahardjo, 2005). The major molds associated with Daqu fermentation can be categorized into two groups. The first group belongs to the family of Mucoraceae. These are known as strong amylase producers in amylolytic Asian fermentation starters (Rahardjo, 2005). Of these fungal species, L. corymbifera occurred during stage 5 and persisted until the end of the fermentation. The relatively high core temperature of the Daqu above $45{ }^{\circ} \mathrm{C}$ during stages 4-5 allows only thermophilic or thermotolerant fungi to survive. This may be true for $L$. corymbifera that has been reported to grow at temperatures as high as $48-52{ }^{\circ} \mathrm{C}$ (Weitzman et al., 1995), and may explain that it was detected during the last three stages of Daqu fermentation. The second group comprises Aspergillus spp., which are used in solid state fermentations and also are known to produce extracellular proteolytic and saccharolytic enzymes (Rahardjo, 2005).

In this study, both culture-dependent and culture-independent approaches were combined to analyze the dynamics of microbial communities during Daqu fermentation. Although both techniques may provide different results due to the use of various sampling methods, they showed sufficient overlap of information on the dominant groups of microbial communities. Only 6 bacterial species, i.e. B. cereus, B. licheniformis, B. megaterium, B. pumilus, B. subtilis and Lactobacillus plantarum and 2 fungal species, i.e. P. kudriavzevii and $W$. anomalus could be detected by both approaches. By the culture independent method, no bands were identified as filamentous fungi. We assume that the absence of bands for filamentous fungi in our DGGE gel is mainly caused either by (1) inadequate DNA extraction of filamentous fungi from the complex food matrix of Daqu, or (ii) by the presence of high concentrations of competing DNA, such as that from yeasts in Daqu. These results reinforce the necessity of employing both culturedependent and culture-independent approaches to uncover the microbial diversity of complex microbial ecosystems, such as Daqu.

Li et al. (2013) applied cloning methods to analyze the microbial communities during the production of Fen-Daqu, and they reported the predominance of lactobacilli and P. kudriavzevii in Daqu. However, our study showed the predominance of different groups of microorganisms at different stages of the fermentation. In conclusion, a succession in relative abundance of fungi, LAB and Bacillus spp. was observed during the Daqu fermentation process, which can be linked to changes in environmental conditions such as $\mathrm{pH}$, temperature, acidity and moisture content (Fig. 1). Better knowledge of microbial succession driven by environmental changes may facilitate long-term technological developments and innovation that will benefit the liquor and vinegar industry.

Supplementary data to this article can be found online at http://dx. doi.org/10.1016/j.jifoodmicro.2014.05.008.

\section{Acknowledgements}

This project was supported by the Specialized Research Fund for the Doctoral Program of Higher Education (No. 20130008110013) and grant KNAW-China Joint Research Project 07CDP015 of the Royal Netherlands Academy of Arts and Sciences.

\section{References}

Burgess, S.A., Lindsay, D., Flint, S.H., 2010. Thermophilic bacilli and their importance in dairy processing. Int. J. Food Microbiol. 144, 215-225.

Chi, Z., Chi, Z., Liu, G., Wang, F., Ju, L., Zhang, T., 2009. Saccharomycopsis fibuligera and its applications in biotechnology. Biotechnol. Adv. 27, 423-431.

Deng, L.F., Fan, X.S., Wang, J.Q., 2012. Fermented soybean meal by Bacillus subtilis and its fermentation condition optimized. China Animal Husbandry \& Veterinary Medicine (in Chinese) 39, 110-114.

Han, Y.Q., 2007. Where is the way of vinegar industry. China Brewing (In Chinese) 167, $73-75$.

Lei, Z., 2011. Preliminary analysis of the change of microbes in the fermentation process of Fenjiu Daqu. Liquor Making Science \& Technology (in Chinese) 6, 65-68.

Li, H., Huang, W., Yi, B., Yang, J., Yang, P., 2012. Ethanol/moisture contents in fermented grains and their effects on the yield and quality of Chinese Luzhou-flavor liquor. Adv. Mater. Res. 396-398, 1605-1610.

Li, X.R., Ma, E.B., Yan, L.Z., Meng, H., Du, X.W., Quan, Z.X., 2013. Bacterial and fungal diversity in the starter production process of Fen liquor, a traditional Chinese liquor. J. Microbiol. 51, 430-438.

Lima, L.J.R., van der Velpen, V., Wolkers-Rooijackers, J., Kamphuis, H.J., Zwietering, M.H. Nout, M.J.R., 2012. Microbiota dynamics and diversity at different stages of industrial processing of cocoa beans into cocoa powder. Appl. Environ. Microbiol. 78 2904-2913.

Rahardjo, Y.S.P., 2005. Fungal mats in solid-state fermentation, Wageningen University Wageningen (http://edepot.wur.nl/121648)

Wang, H.Y., Gao, Y.B., Fan, Q.W., Xu, Y., 2011. Characterization and comparison of microbial community of different typical Chinese liquor Daqus by PCR-DGGE. Lett. Appl. Microbiol. 53, 134-140.

Weitzman, I., Whittier, S., McKitrick, J., Della-Latta, P., 1995. Zygospores: the last word in identification of rare or atypical zygomycetes isolated from clinical specimens. J. Clin. Microbiol. 33, 781-783.

Wu, X.H., Zheng, X.W., Han, B.Z., Vervoort, J., Nout, M.J.R., 2009. Characterization of Chinese liquor starter, "Daqu" by flavor type with1H NMR-based nontargeted analysis. J. Agric. Food Chem. 57, 11354-11359.

Wu, Q., Xu, Y., Chen, L., 2012. Diversity of yeast species during fermentative process contributing to Chinese Maotai-flavour liquor making. Lett. Appl. Microbiol. 55, 301-307.

Yan, Z., Zheng, X.W., Han, J.S., Han, B.Z., Nout, M.J.R., Chen, J.Y., 2013. Monitoring the ecology of Bacillus during Daqu incubation, a fermentation starter, using culturedependent and culture-independent methods. J. Microbiol. Biotechnol. 23, 614-622.

Zhao, Z.L., Ma, X., Yuan, C., Li, Y., Li, S.Y., 2011. Isolation and identification of three strains with $\beta$-mannanase activity. J. Henan Agric. University (in Chinese) 45, 684-687.

Zheng, X.W., Tabrizi, M.R., Nout, M.J.R., Han, B.Z., 2011. Daqu-a traditional Chinese liquor fermentation starter. J. Inst. Brew. 117, 82-90.

Zheng, X.W., Yan, Z., Han, B.Z., Zwietering, M.H., Samson, R.A., Boekhout, T., Nout, M.J.R. 2012. Complex microbiota of a Chinese "Fen" liquor fermentation starter (Fen-Daqu), revealed by culture-dependent and culture-independent methods. Food Microbiol. 31, 293-300. 